\title{
A Web-based SMART STORE Platform for collaborative supply chain integration
}

\author{
S.K. Kwok, W.B. Lee and C.F. Cheung \\ Department of Industrial and Systems Engineering, The Hong Kong Polytechnic University, \\ Hung Hom, Kowloon, Hong Kong.
}

\begin{abstract}
The globalization of world market leads to the increasing demand for the use of Internet technology for supporting logistics and supply chain activities for many manufacturing enterprises. In this paper, a web-based smart store infrastructure is proposed for collaborative supply chain integration. The infrastructure incorporates various latest networking, mobile commerce and collaborative technologies for facilitating data communications, sharing and information management of complex logistics and supply chain management processes under a distributed environment. A prototype smart store system has been built.
\end{abstract}

\section{Keywords}

E-logistics, supply chain integration, mobile commerce, collaborative platform, order processing and tracking, order fulfilment.

\section{INTRODUCTION}

Despite the publicized importance of e-Logistics [1] and supply chain management (SCM) [2] to the future competitiveness of business, the adoption of ebusiness technology by manufacturing enterprises, especially among the small and medium sized enterprises (SMEs) is still far from satisfactory. Many enterprises are still immune from the use IT technologies to improve their logistics and supply chain activities. This is due to the fact that most SMEs are lack of fully integrated systems to handle the complex business processes from order management, manufacturing down to logistics and supply chain management. They usually operate under various constraints of the technical, financial and human resources.

Nowadays, there is a tendency that more enterprises evolve into loosely tied and decentralized federations or business units, making products and seeking alliances both within and outside the consortium to serve customer's demands to their best ability $[3,4]$. The supply chain activities in such kind of networked enterprises can cut across various functional sectors within and outside the enterprise and the information processing is usually organized along these functional sectors in geographically different locations. As shown in Table 1, those activities involve complex data communication, information flow, negotiation, arbitration, supplier selection [5], planning and decision making, production control and collaboration 
among various parties in a supply chain. There is a need to develop an affordable and easily customizable collaborative platform for the integration of various supply chain activities among different functional business units in a dispersed networked environment. In this paper, a web-based smart store platform is proposed for collaborative supply chain integration.

Table 1 - Information flows for supply chain activities

\begin{tabular}{|c|c|c|c|}
\hline Business entity & $\begin{array}{c}\text { Information managed } \\
\text { within the entity }\end{array}$ & $\begin{array}{l}\text { Information } \\
\text { Exchanged } \\
\text { upstream }\end{array}$ & $\begin{array}{l}\text { Information } \\
\text { exchanged } \\
\text { downstream } \\
\end{array}$ \\
\hline $\begin{array}{l}\text { Material } \\
\text { Suppliers }\end{array}$ & $\begin{array}{l}\text { Inventory level } \\
\text { Pricing }\end{array}$ & & $\begin{array}{l}\text { Issue invoices to } \\
\text { manufacturers } \\
\text { Issue delivery } \\
\text { notice to } \\
\text { manufacturers }\end{array}$ \\
\hline Manufacturers & $\begin{array}{l}\text { Inventory level of } \\
\text { materials } \\
\text { Inventory level of } \\
\text { finished goods } \\
\text { Pricing of products } \\
\text { Costs of materials } \\
\text { Labour and machine } \\
\text { capacity and schedule } \\
\text { Outstanding sales orders } \\
\text { Outstanding purchase } \\
\text { orders }\end{array}$ & $\begin{array}{l}\text { Issue purchase } \\
\text { orders to material } \\
\text { suppliers } \\
\text { Issue goods } \\
\text { receipt notice to } \\
\text { material suppliers }\end{array}$ & $\begin{array}{l}\text { Issue invoices to } \\
\text { distribution centres } \\
\text { Issue delivery } \\
\text { notice to } \\
\text { distribution centres }\end{array}$ \\
\hline $\begin{array}{l}\text { Distribution } \\
\text { Centres }\end{array}$ & $\begin{array}{l}\text { Inventory level of retail } \\
\text { items } \\
\text { Pricing } \\
\text { Outstanding } \\
\text { replenishment orders } \\
\text { Outstanding purchase } \\
\text { orders }\end{array}$ & $\begin{array}{l}\text { Issue purchase } \\
\text { orders to } \\
\text { manufacturers } \\
\text { Issue goods } \\
\text { receipt notice to } \\
\text { manufacturers }\end{array}$ & $\begin{array}{l}\text { Issue invoices or } \\
\text { replenishment order } \\
\text { acknowledgements } \\
\text { to the retail outlets } \\
\text { Issue delivery } \\
\text { notice to } \\
\text { distribution centres }\end{array}$ \\
\hline Retail Outlets & $\begin{array}{l}\text { Inventory level of retail } \\
\text { items } \\
\text { Pricing } \\
\text { Outstanding } \\
\text { replenishment orders }\end{array}$ & $\begin{array}{l}\text { Issue } \\
\text { replenishment } \\
\text { orders to } \\
\text { respective } \\
\text { distribution centre } \\
\text { Issue goods } \\
\text { receipt notice to } \\
\text { distribution centre }\end{array}$ & $\begin{array}{l}\text { Issue payment } \\
\text { receipt to the } \\
\text { customers }\end{array}$ \\
\hline Consumers & & $\begin{array}{l}\text { Check out the } \\
\text { goods in cashier } \\
\text { counters in retail } \\
\text { outlet }\end{array}$ & \\
\hline
\end{tabular}




\section{INFRASTRUCTURE OF THE SMART STORE PLATFORM}

Collaborative supply chain integration involves the use of Internet technology to the coordination of a wide scope of complex logistics and supply chain activities which include order processing, inventory management, order fulfilment, collaborative planning, forecast and replenishment, etc. In order to increase the operational efficiencies, various networking, hardware, software and data communication technologies are needed.

Figure 1 shows a proposed infrastructure of a smart store platform which is developed based on an eight-tier infrastructure. It includes data acquisition and transmission tier, personalized web interface tier, web server tier, networking tier, collaborative operations tier, integrated applications tier, data interchange tier and data warehouse tier. Additional functions and application modules can be incorporated in the integrated application tier.

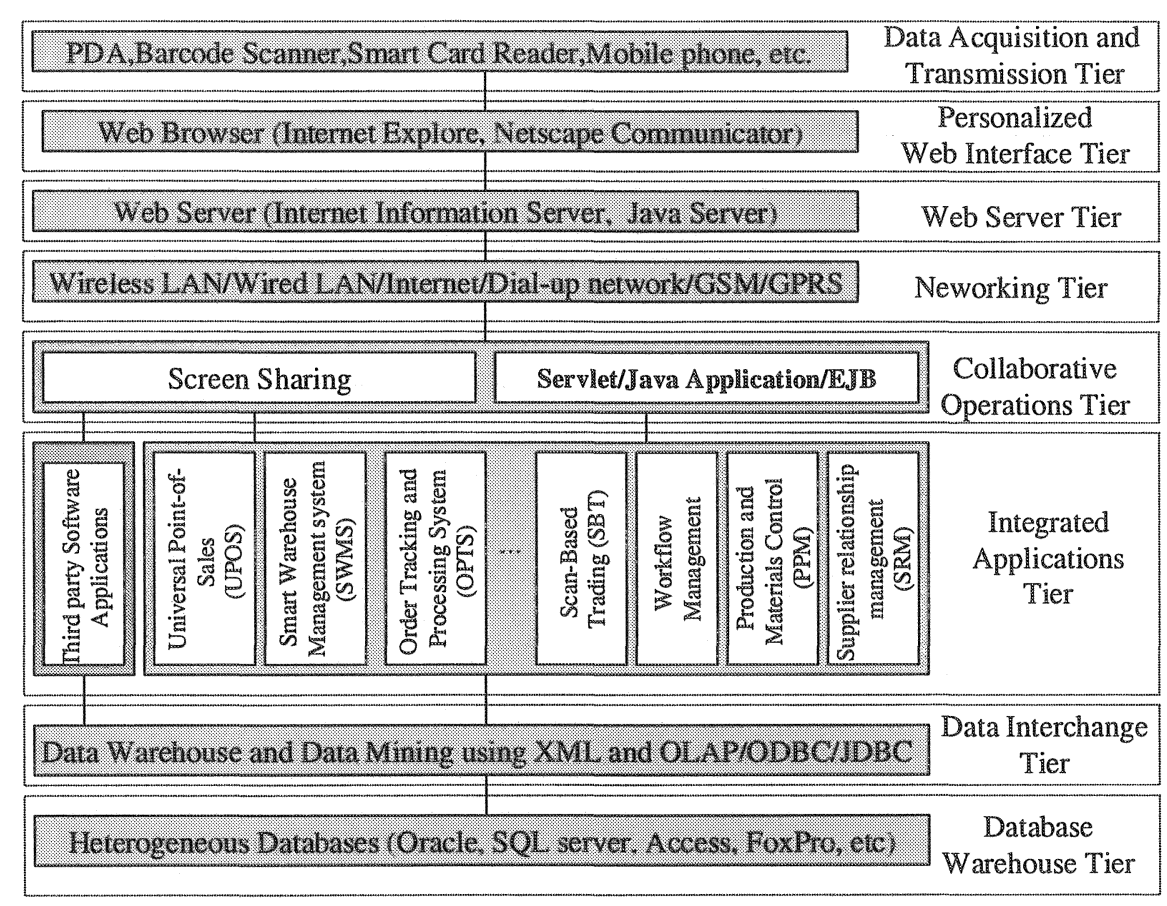

Figure 1 - Infrastructure of the web-based smart store platform

\section{Data Acquisition and Transmission Tier}

Data acquisition tier is designed as the hardware interface that permits input/output devices such as video cam, remote printer, barcode scanner, smart card reader, $\mathrm{RF}$ contact and contactless readers, hand held devices such as Personal Data Assistant as well as mobile phone for supporting data acquisitions and transmissions. The acquired and transmitted data are used to support other tiers of 
the platform. In other words, the first tier handles the physical connection to the platform and the sending and receiving of signals, whether electrical or optical.

\section{Personalized Web Interface Tier}

The personalized web interface tier gives individuals, business entities and teams the tools they need to access, organize and share mission-critical information, collaborate securely from distributed locations and make faster, better-informed decisions. A library of built-in templates is provided for rapidly customizing the optimal work environment within the platform using a standard web browser. The built-in templates offer reusable structure, content and tools that allow the personalization of user interface for different applications.

\section{Web Server Tier}

Web service to the browser is provided by the web server tier. The Java server is used to provide the web service while the media server is used to provide multimedia application services. Java server pages (JSP) and Java servlets are used to produce dynamically web pages and communicate with the backend database and integrated applications.

\section{Networking Tier}

The networking tier provides universal networking modes for supporting data communication mode under both wired and wireless network environments such as IEEE802.11b wireless LAN, mobile phone network, modem-dialup, blue tooth, wired LAN, internet, virtual private network (VPN), etc. The selection of networking environment largely depends on the supply chain activities being undertaken. For example, wireless LAN is more suitable than wired LAN for the inventory management operations inside large distribution centre and warehouse.

\section{Collaborative Operations Tier}

The collaborative operation tier provides a robust platform for customizing and developing applications that employ instant collaboration. The users can embed instant collaborative capabilities into integrated software applications preinstalled in the application server. This is accomplished by a screen sharing and refreshing algorithm. The screen sharing technologies [6] allows multi-users to remotely share control of the server screen, mouse, keyboard and server applications such as production planning and control, inventory management and scan-based trading. A number of participants among the supply chain can conduct collaborative operations such as manipulating point-of-sales data, inventory record, negotiate purchasing contracts by sharing the server's computer resources-while the user looks on and participates. 


\section{Integrated Applications Tier}

Integrated applications tier provides services to support specific native and third party e-logistics applications. The former refers to the in-house developed specific software applications such as inventory management, global point-of-sales, workflow management, order tracking and processing system, short message system and electronic payment systems. They are running in a native mode in the platform. The later refers to the market available software applications.

\section{Data Interchange Tier}

The implementation of the smart store platform needs a common standard for interchange of data over heterogeneous platforms used by different supply chain entities. The data interchange tier is designed to make it easy to incorporate data from multiple sources in multiple formats, and to organize data in a consistent way [7]. Extensible markup language (XML) is a new standard that formalizes the semantics of the contents of web files and facilitates electronic data interchange (EDI) [8].

An XML schema with a neutral format can be customized to suit various elogistics software packages. A generic XML format converter will be used so that the format conversion can be accomplished from neutral standard to a companyspecific data standard or vice versa. The format converter is generic in the sense that enterprises can customize it through a group of built-in functions to suit the specific format used by individual company.

\section{Data Warehouse Tier}

The data warehouse tier is composed of a series of databases and adapters are built for the conversion of the data from different data formats for different business entities to a common plain text format which is accessible to the data interchange tier.

\section{IMPLEMENTATION AND APPLICATIONS}

A prototype of Smart Store platform has been built based on the infrastructure described previously. The capabilities of the prototype have been evaluated through integrated applications in universal point-of-sales (UPOS), smart warehouse management, order tracking and processing (OPTS) as shown in Figure 2.

The universal point-of-sales (UPOS) is a generic information system for retail business that makes use of the latest barcode scanning and smart card payment technologies for order processing in retail outlets of an enterprise located in geographically different locations. It supports multiple operation modes ranging from standalone system to web-based operations. The smart store warehouse management system (SWMS) utilizes innovative hybrid devices that combine both PDA and barcode scanner functions can facilitate goods check-in, check-out, 
compartment loading and unloading operations in large warehouses and distribution centres. For the order processing and tracking system (OPTS), it implements extensive order tracking and processing that greatly automates traditional manual inventions in business-to-business order collaborations. The system also makes use of short message system (SMS) to alert procurement workers of any problems in order fulfilment.

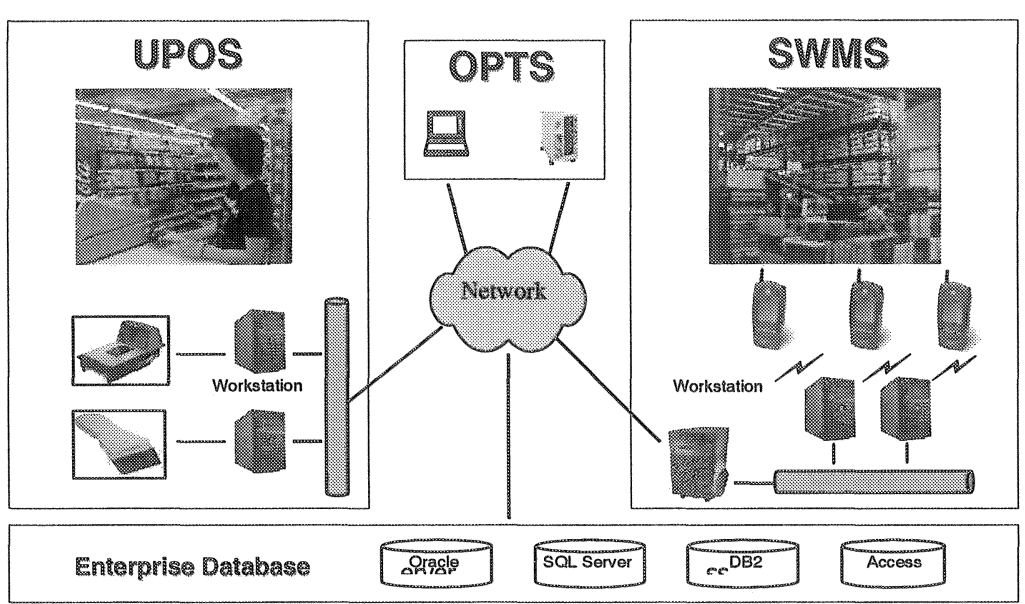

Figure 2-Integrated applications of the web-based Smart Store platform

\section{Universal Point-of-Salles (UPOS)}

As shown in Figure 3, the Universal Point-of-Sales (UPOS) developed by the Smart Store project is a full-blown retail information system that facilitates barcode scanning, smart card payment and support multiple operating modes ranging from stand alone system to web-based operations. For global supply chain operations, the supply chain entities such as retail outlets, distribution centres, manufacturing plants, suppliers and headquarters are very often located in geographically different locations. The networking environment for different locations may be different due to the constraints of the local network facilities and service providers. For examples, Shop A in Hong Kong may easily get access to broadband Internet service, while Shop B in Mainland China may only support a dial-up data connection. As a result, the UPOS is built with generic capability to cater for different network environments. 


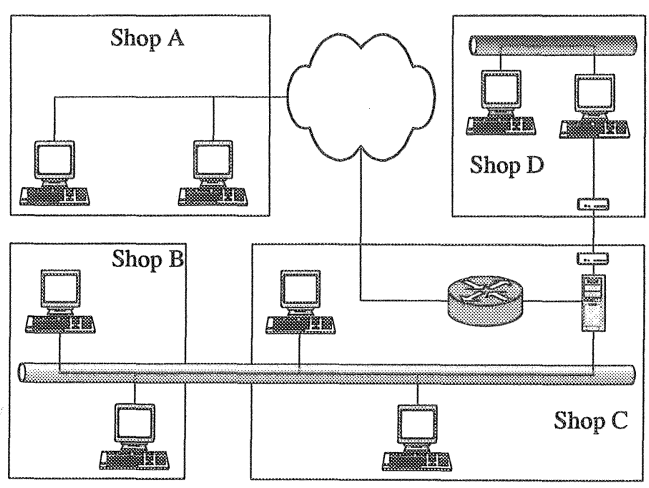

Figure - 3 Schematic diagram of UPOS

It can be operated under a standalone mode, which does not need to have any outside connections. For Internet mode, UPOS can be run in a remote computer host and a payment counter at the retail outlet can access the functions of the UPOS using a local terminal connected to the remote host through the Internet. Similar to the Internet mode, UPOS applications can also be run at one side of a LAN and a payment counter accesses the functions of the UPOS using a local terminal set up at another side of the LAN. The data communication can also be accomplished with Dial-up network and the local terminal at the payment counter connects to the remote UPOS host by using modem-dialup connection.

\section{Order Processing and Tracking System (OPTS)}

Figure 4 shows a schematic diagram of the OPTS used in the Smart Store infrastructure. The OPTS provides extensive order processing and tracking functions that facilitates the automation of the workflow of business processes such as order processing, order status tracking, inventory monitoring and replenishment, supplier performance monitoring, etc. The purchase and replenishment orders generated by the OPTS can be stored in electronic formats and accessed by both the buyer and the supplier through the web. Any routine changes to the status, ordered quantities and types of items can be made through the web interface and the changes can be updated and reflected in real-time. Such a revolutionary way of business collaboration greatly reduces order processing time and significantly improves operation efficiencies at both the buyer and supplier ends. 


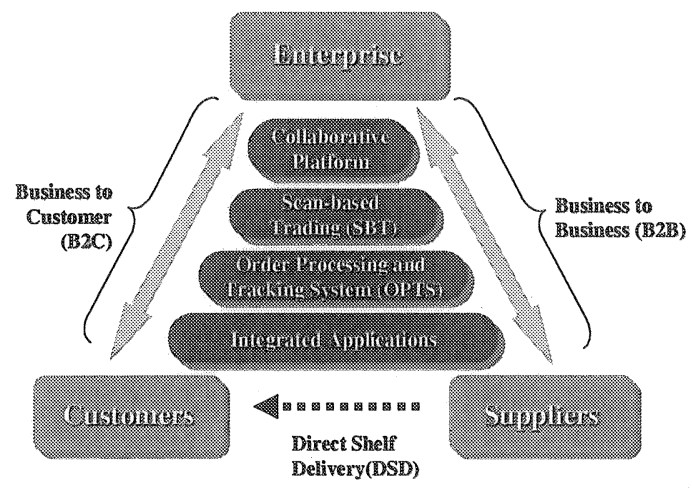

Figure 4 - A schematic diagram of the OPTS [1]

In many occasions, procurement staff working in a distribution centre needs to devote considerable time and effort to keep track of what happens after a purchase order is issued to a supplier. He has to ensure the supplier has received and started processing the order be sent. He needs to be alerted when the tentative delivery date has passed and the supplier has not yet delivered the ordered goods. He also needs to be alerted if the actual types and quantities of received items are deviated from that stipulated in the original purchase order. The OPTS is continuously tracking for the statuses of all outstanding orders anytime and anywhere. It can automatically generate necessary alert messages in response to any problems in order fulfilment and send the alerts to designated staff using the Short Message System (SMS) service provided by mobile phone operators. The use of SMS alert function enables the staff-in-charge to take immediate actions against any problems at the earliest stage.

\section{Smart Warehouse Management System (SWMS)}

Warehouses are major facilities operated by typical distribution centres in a supply chain. The major activities in a warehouse always include goods check-in, check-out, compartment loading and unloading. The Smart Warehouse Management System (SWMS) has sophisticated functions to handle these activities as shown in Figure 5. 

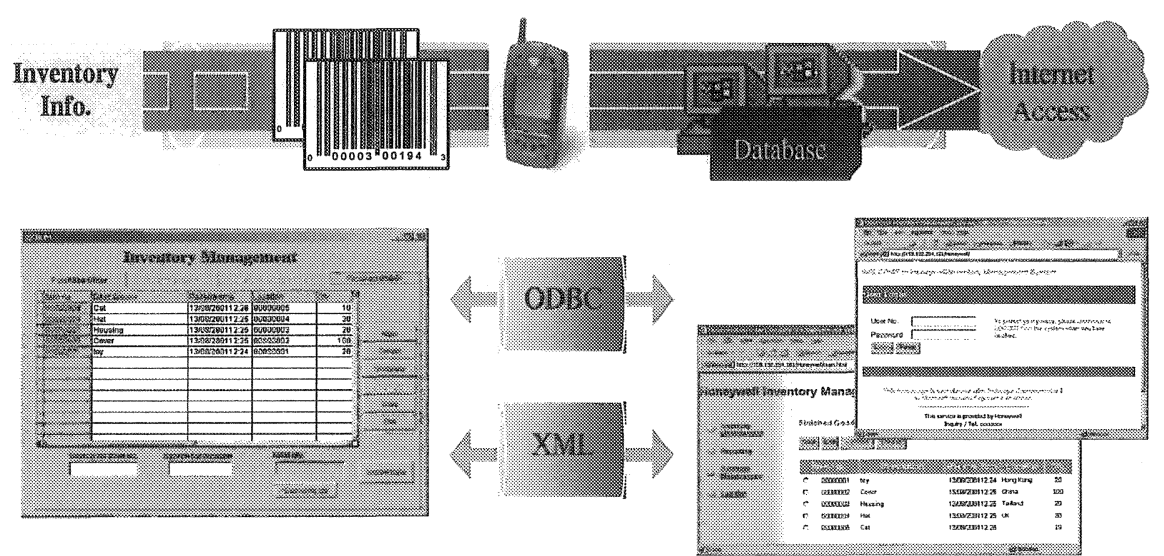

Figure 5 A block diagram of the Smart Warehouse Management System (SWMS)

When a batch of ordered items arrives at a warehouse, the staff of the warehouse need to scan the barcode label on the received goods and check the quantities of the items received. SWMS has a check-in function to perform this operation. After the items have gone over the check-in procedure, the information scanned will be sent to the SWMS host computer to update the inventory database. The goods check - out procedure is just the reverse of the goods check-in and the compartment unloading procedure is just the reverse of compartment loading.

The SWMS maintains not only the inventory database of goods stored in the warehouse, but also keeps track of the whereabouts of each item. Each compartment in the warehouse is assigned a unique location code, and is represented by a barcode label placed at the edge of the compartment. When a staff loads some received items into a particular compartment, he will also use a barcode scanner to scan the barcode attached to that compartment. This record will then be uploaded to the SWMS host computer to update the location information of the received goods.

\section{Collaborative supply chain integration}

Collaborative supply chain refers to the use of Internet for supply chain entities to collaboratively manage the dispersed supply chain activities among different business partners located in geographically different locations. Very often, inventory data, bill of materials and product specifications at different stages of a supply chain such as packaging need to be changed and customized for the changing demand and customer needs. In order to achieve a better utilization of the available resources at dispersed locations so as to accommodate the corresponding changes, members of the project team have to work simultaneously or sequentially on the large amount of product and inventory data. For example, repackaging and consignment of products are required for the inventory, which have already been assigned for customer in Japan so as to fulfil the urgent demand for another customer in UK. This demands the use of collaborative technologies for real-time allocation/consignment of resources/inventory under a distributed environment. As discussed earlier, the proposed Smart Store infrastructure provides collaborative functions for the supply 
chain partners to share, amend and operate different integrated applications in a realtime and synchronized mode so as to improve the efficiency of the supply chain processes. Figure 6 shows a scenario of collaborative inventory management between a supplier and a manufacturer working in geographically different locations.

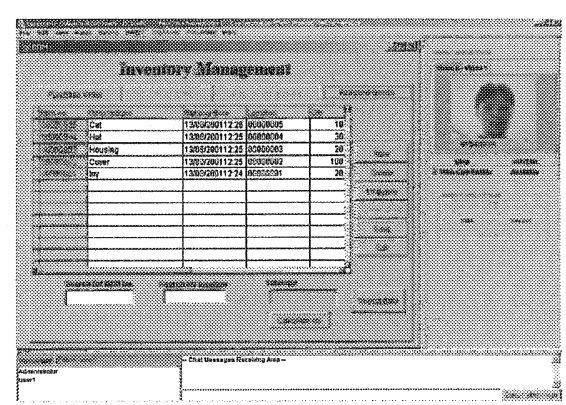

Supplier's Office (UK)

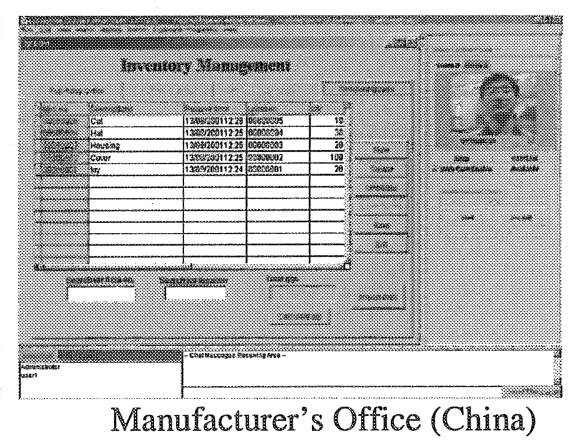

Manufacturer's Office (China)

Figure 6 - A scenario of collaborative inventory management

\section{CONCLUSIONS}

The traditional logistics and supply chain management model based on human workforce has no longer been adequate to satisfy the customer needs and cope with the radically changing global business environment. This paper focuses on the development of an infrastructure of a web-based Smart Store platform for increasing the efficiency of enterprises to manage the diverse logistics and supply chain activities among its customers and business partners. In essence, the Smart Store platform is an internet-based communication platform to enable geographically dispersed users to manage the logistic and supply chain activities which include inventory management, order processing and tracking as well as the management of supply chain activities among internal and external suppliers. The successful development and applications of the infrastructure will help spread the use of collaborative technology in supply chain integration for geographically dispersed networked enterprises.

\section{ACKNOWLEDGEMENT}

The authors would like to express their sincere thanks to the Research Committee of The Hong Kong Polytechnic University for financial support of the research work (Project No.: H-ZD28). 


\section{REFERENCES}

[1] Cheung, C.F., Kwok, S.K. and Lee, W.B., "E-collaborative Technologies and Its Applications in e-Logistics", Asian Industrial Technology Congress (AITC), Technology Digest, 29-30 August, Hong Kong, pp. 47 - 50. (2002)

[2] Lamming, R.C., Johnsen, T., Zheng, J. and Harland, C., "An initial classification of supply networks", International Journal of Operations and Production Management, Vol 20, No. 6, pp. 675 - 691. (2000)

[3] Lee, W.B., Cheung, C.F., Lau, H.C.W. and Choy, K.L., "Development of a Web-based Enterprise Collaborative Platform for Networked Enterprises," paper accepted, to be published in Business Process Management Journal. (2002)

[4] Lee, W.B. and Lau, H.C.W., "Multi-agent Modelling of Dispersed Manufacturing Network", Expert Systems with Applications, Vol. 16, pp.297 - 306. (1999)

[5] Lin, F.R., Tan, G.W. and Shaw, M.J., "Modelling Supply Chain Networks by a Multiagent System", Proceedings of the 31st Annual Hawaii International Conference on System Science, pp. 105 - 114. (1998)

[6] Zhan, H.F., Lee, W.B., Cheung, C.F., Gu, X.J. and Kwok, S.K., "A Web-based Collaborative Product Design Platform for Dispersed Network Manufacturing", paper accepted, to be published in Journal of Materials Processing Technology. (2002)

[7] Needleman, M.H., "XML", Serials Review, Vol. 25, Issue 1, pp.117 - 121. (1999)

[8] Brandl, D.L., "ISA SP95: The factory-to-business link", Industrial Computing, Vol.19, Issue $6, \mathrm{pp} \cdot 16-17 .(2000)$ 